not find himself so strong as he used to be, and kept gradually getting worse, till about six weeks before his admission, when he was obliged to give up his work. Latterly, he had three or four times passed blood with his urine. During the first week. in October, he applied to Mr. Ball for advice, who, after seeing him a few times, recommended him to come into the Infirmary, and he was accordingly admitted on the 1Sth of October, when his symptoms were as follows:--Congh; great difficulty in breathing, much increased on lying dowa; ascites; general anasarea; great blueness of the fice and extremities, with anxiety of countenance; no appetite; bowels costive; sounds of the hear' very tumultuous; pulse weals and laboured; urine scanty, with an acid reaction; sp. gr. $1 \cdot 009$; no albumen.

Oct. 19th. - He was ordered to take two scruples of compound jalap powder -every morning, and a diuretic draught three times a day.

21st.-Bowels open, and urine more abundant, but feels very weak; cough and difficulty of breathing rather worse. Ordered a blister to the ehest, and to contimue the medicines.

23rd. -No improvement.

25th. - Worse. Has voided a considerable quantity of blood per urethram. To have dry cupping-glasses applied to the loins, and five grains of gallic acid three times a day.

27th.-The hæmaturia abated this evening, but all the other symptoms were much aggravated.

28th.-Much worse; congestion of countenance increased; extremely restless; almost unconscious.

29 th. - Worse; totally unconscious. In this state he lingered till the next morning, when he died at eight A.M.

Autopsy. - On opening the chest, the lungs appeared to be healthy; crepitating under the fingers, and free from any pleural adhesions; on cutting into them, however, there were found several encephaloid masses, varying from the size of a pea to that of a small walnut, and readily turning out of their cysts. The heart appeared to be nearly double the usual size, flabby to the touch, and of a pale colour; it weighed twenty. one ounces. Two of the pulmonary semilunar valves were united by their edges to nearly the corpora arantii by a cartilaginous substance about the size of a small pea, in which ossification had commenced. The spleen, pancreas, stomach, and intestines, presented nothing unusual. The liver contained several encephaloid masses similar to those in the lungs; size natural. The left kidney was an enormons size, weighing no less than five pounds four ounces, and was held in its situation by such firm adhesions, that the diaphraghm and some of the surrounding structures were torn, and it was with much difficulty removed from the body. The mass, which was medullary, appeared to have grown from the upper part of the liidney and renal capsule, most of the lower cones and the yelvis of the kidney appearing quite healthy. The renal vein on this side was much enlarged. The opposite kidney was quite healthy, and weighed seven ounces and $a$ half. There was nothing unusual about the bladder. The head was not allowed to be opened. The preparations were exhibited at the anniversary meeting of the North Staffordshire Medical Society.

\section{VACCINATION EXTENSION ACT.}

\section{To the Editor of TeE LANCET.}

SrR,-As the law now enforces universal vaccination, the attention of the profession will be more immediately directed to it, and surely they will find that, whatever benefits it may confer upon the community, it will prove to them a source of no little annoyance and trouble. Under the provisions of the Act they will be compelled to grant the eertificates required, and if they are not appointed public vaccinators, will receive, in the majority of instances, merely the thanks of those who require their services. In this union (Dewsbury) it has been customary with the bulk of medical men to vaccinate gratuitously their poorer patients, and now to be called upon to grant them a certificate, as well as transmit one to the registrar, is a hardship indeed. True, some will say, you must make a charge for the operation, or send them to the appointed offeer. Such a mode would be infair to adopt; and the only means to make the Act a just one will be to appoint every qualified man a public vaccinator. This has been done in some unions, and all honour to the guardians is certainly due for their proper appreciation of our claims. In this district the walls have been placarded, to point out to the people that vaccination is not only compulsory but gratuitous, telling them that they are under a fine if they neglect to have their children vaccinated, and ending with the information, that no charge WHATEVER will be incurred if they take them to the gentlemen whose names are appended to the document. This is not all. When a child is registered a printed paper is given to its guardians, in which is written the name of the appointed vaccinator, and the places he attends for vaccination. This, though required by the Act, is a species of advertisement, and an act of injustice to what are termed in it, duly-qualified medical attendants. We are all in possession of the books required to be kept, and in addition are to send the duplicate to the registrar, with the modest request, if we are unable to deliver them personally, to transmit them unpaid by post.

A meeting, convened by circular, was held here on the 25th ult., to consider what steps should be taken by those who are not appointed public vaecinators; and after reading letters from those unable to attend, it was ultimately resolved that a memorial be sent to the Secretary of State, pointing out the injustice of the present Vaccination Act towards a large body of the profession, petitioning that all legally-qualified practitioners be recognised as public vaceinators, and paid by the boards of guardians, upon the same terms as the vaccinators now contracted with by them, and that a similar memorial be sent to the Dewsbury Board. The meeting likewise considered that, under existing circumstances, it was not advisable to recommend any particular line of proceeding to their medical brethren, but that each should pursue such oourse as he might consider necessary. The contracts in this union will end in March next, and we shall then know whether we are still to endure what we are now labouring under. Your powerful pen has often been wielded in defence of our rights, and your advice has frequently led the majority of the profession, and we should be happy to hear your sentiments upon what concerns all the members of our common profession.

I am, Sir, yours obediently,

Heckmondwike, Dec. 1853 . T. B. OLDFIELD, M.R.C.S., L. A.C.

\section{ST. BARTHOLOMEW'S HOSPITAL-ANOTHER GRIEVANCE.}

To the Editor of THE LANCET.

Sir,-Some months ago there appeared in your columns a series of letters relative to the grievances in the College of St. Bartholomew's Hospital. Owing to the exertions of the present Warden, many of these have been redressed; but, of late, a new one has arisen.

When a student enters the college, he signs a declaration, by which he pledges himself to obey all the rules thereof. In these there is nothing relative to his account being paid in advance : nevertheless, within the first month of residence, he receives his account "for rent and commons ;" and is requested to pay it on or before a certain day. If this is not done, he receives, after the lapse of a few days, another copy of the account, headed, "Second Application," naming another day for payment.

Looking from my tower this morming, I saw one of the hospital servants issuing from the clerk's office, bearing a number of letters addressed to those gentlemen resident in college who have not yet paid their bills, which are due on the 24th inst. One of these documents has reached me, and I send you a copy. It is as follows:-

"St. Bartholomew's Hospital.

"SIR,-II beg to remind you that your account for rent and commons in the collegiate establishment, $\&$ (here follows the amount), to the 24th December, has been twice transmitted to you, and still continues unsettled.

"I have, therefore, to request your early attention to the settlement of this account, since it will be my duty to submit the same to the Treasurer and Governors on the $22 \mathrm{nd}$ inst., unless the same be paid before that day.

"Clerk's Office, Dec. 12, 1853." “JoHN RUgSELL ClIPPERTON.

Never, Sir, since my elevation, have I seen so disgraceful a production issue from beneath me, one so insulting to the feelings of a gentleman. For what reason can this payment in ad. vance be insisted on? Surely not for the sake of the interest of the money for the two or three months which elapse between payment and the time when the bill becomes due! And if not this, there only remains the supposition that the "Treasurer and Covernors" do not consider the college students, or their guardians, honourable or solvent enough to meet their just debts. If this be the true reason, I would beg to suggest that the following should be inserted among the College Rules which are signed by the student on entry :- "I engage to find surety to the amount of $£ 200$, to pay my bill when it becomes due." I am, Sir, your obedient Servant,

St. Bartholomew's Hospital, Dec. 12, 18̄̄3.
"The C THO 